\section{A) Check for updates}

Cite this: Food Funct., 2020, 11, 4081

\title{
Evaluation of the impact of a rat small intestinal extract on the digestion of four different functional fibers
}

\author{
Pablo Gallego-Lobillo, Alvaro Ferreira-Lazarte, Oswaldo Hernández-Hernández, (D) * \\ Antonia Montilla (D) and Mar Villamiel (D)
}

\begin{abstract}
The degree of digestion, modulated by rat small intestinal extract on different functional fibers was investigated. In general, inulin-type fructans and fructooligosaccharides were the most resistant to the enzymatic digestion. Results evidenced the high-resistance of fructosyl-fructose bonds. This fits well with the concept of prebiotic carbohydrates. However, the mixture of melibiose, manninotriose and verbascotetraose $(\alpha-G O S)$ from peas, with a considerably lower molecular weight $(0.6 \mathrm{kDa})$ than the fructans studied, were highly digested (61.2\%). Interestingly, the Gal-(1 $\rightarrow 6)$-Gal bonds present into the manninotriose and verbascotetraose were more prone to be hydrolyzed than Gal-(1 $\rightarrow$ 6)-Glc (melibiose). However, when melibiose was the only disaccharide present in the reaction mixture, the hydrolysis was also high (67.7\%). The use of small intestinal enzymatic preparations is a realistic approximation to evaluate the digestion of different carbohydrates, thus, showing that recognized non-digestible carbohydrates can also be partially digested.
\end{abstract}

Received 27th January 2020,

Accepted 20th April 2020

DOI: $10.1039 / \mathrm{d} 0 \mathrm{fo} 00236 \mathrm{~d}$

rsc.li/food-function natural sources mainly agro-food by-products. Once the functional fiber is produced is added to food during processing with the aim of providing beneficial effects on human health. Functional fibers include polysaccharides such as $\beta$-glucans, cellulose, chitins and chitosan, fructans, gums, pectin, polydextrose, polyols, resistant dextrins, resistant starches and oligosaccharides that are resistant to digestion. ${ }^{2}$

According to previous studies, these carbohydrates can reach intact the large intestine, where they are hydrolyzed and fermented by the intestinal microbiota, thus causing the production of short chain fatty acids (SCFAs) that exert a beneficial effect not only in the colon but also systemically. ${ }^{6-8}$ However, few studies have been conducted on the digestive resistance of carbohydrates (also refereed as non-digestible carbohydrates), probably due to the lack of reliable digestion methods specifically designed for carbohydrates.

To date, the focus of the most common approach to simulate the small intestinal digestion is dedicated to proteins, lipids and starch, by using pancreatic enzymes from porcine origin, salivary enzymes and microbial enzymes, which could not reflex most of the carbohydrase activities of the whole small intestine. ${ }^{9}$ The Association of Official Analytical Chemist (AOAC) developed an integrated determination method for dietary fiber, including non-digestible oligosaccharides (NDOs) and resistant starch, which was modified later in 2015 (AOAC 2009.01). ${ }^{10,11}$ Other methods, as well as this method, are based on the use of isolated digestive enzymes. Porcine 
pancreatic $\alpha$-amylase and a fungal amyloglucosidase from Aspergillus niger are used to produce the complete hydrolysis of digestible saccharides, and therefore, to distinguish between digestible and non-digestible carbohydrates. However, similar to the InfoGest protocol, these enzymes cannot completely hydrolyze digestible saccharides since they do not represent the fully complex enzymatic environment of the small intestine, mainly because of the absence of the brush border enzymes of the enterocytes. As a result, digestible saccharides that are not fully degraded are detected as non-digestible carbohydrates, which lead to an inaccurate determination of the digestion resistance of these carbohydrates. ${ }^{12,13}$ Recently, a promising in vitro digestibility method of dietary carbohydrates using rat small intestinal extract (RSIE) has questioned the belief that recognized prebiotics oligosaccharides derived from lactose (GOS) and fructooligosaccharides (FOS) reach the distal portions of colon without alterations. ${ }^{14-16}$ Therefore, with the aim of gain more insight on the benefits of non-digestible carbohydrates, in this work the digestibility of commercial functional fiber, such as $\alpha$-galactooligosaccharides derived from peas and different types of fructans have been tested using a rat small intestine extract.

\section{Materials and methods}

\subsection{Chemical and reagents}

Fructose (Fru) standard was obtained from Fluka Analytical (St Gallen, Switzerland). Analytical standards of D-Galactose (Gal), D-glucose (Glc), maltose ( $\alpha$-D-Glc(1 $\rightarrow 4)$-D-Glc), sucrose $(\beta$-D-Fru( $(2 \rightarrow 1)-\alpha$-D-Glc), phenyl- $\beta$-D-glucoside, pullulan set (805-0.34 kDa), as well as the reagents for Bradford method (Bio-Rad Laboratory Gmbh, Munich, Germany) and intestinal acetone powders from rat (Rat Small Intestine Extract, RSIE) were provided by Sigma-Aldrich (St Louis, MO). Lactose ( $\beta$-D$\operatorname{Gal}(1 \rightarrow 4)$-D-Glc) standard was purchased from ACROS Organics (Geel, Belgium). Melibiose ( $\alpha$-D-Gal(1 $\rightarrow$ 6)-D-Glc) standard was obtained from Thermo Fisher Scientific (Kandel, Germany). Analytical standards of kestose $(\beta-\mathrm{D}-\mathrm{Fru}(2 \rightarrow 1)-\beta-\mathrm{D}-$ $\operatorname{Fru}(2 \rightarrow 1)-\alpha$-D-Glc) and nystose $(\beta$-D-Fru( $2 \rightarrow 1)-\beta$-D-Fru $(2 \rightarrow 1)$ $\beta$-D-Fru(2 $\rightarrow 1)$ - $\alpha$-D-Glc) were supplied by FUJIFILM Wako Chemical Corporation (Neuss, Germany).

\subsection{Prebiotic carbohydrates}

Four types of commercial carbohydrates were used for the digestion assays: Orafti® GR (92\% of inulin and $8 \%$ of FOS with a degree of polymerization (DP) up to 10), Raftiline ${ }^{\circledR}$ High Performance (inulin with an average DP up to 25), Raftilose ${ }^{\circledR}$ P95 (FOS; DP 3 to 7). These carbohydrates were obtained from Orafti S. A. (Oreye, Belgium). In addition, a commercial mixture of $\alpha$-GOS with DP 2-4 (AlphaGOS® P) from Olygose (Venette, France) were tested.

\subsection{Characterization of substrate by HPSEC-ELSD}

The molecular weight $\left(M_{\mathrm{w}}\right)$ of each carbohydrate was obtained by High Performance Size Exclusion Chromatography (HPSEC) coupled to an Evaporative Light Scattering Detector (ELSD), following the method described by Muñoz-Almagro et al. (2018). ${ }^{17}$ Analysis was carried out on a LC 1220 Infinity System (Agilent Technologies, Boebligen, Germany), using two TSK-GEL columns (G5000 PWXL, $7.8 \times 300$ mm, $10 \mu \mathrm{m}$; G2500 PWXL, $7.8 \times 300 \mathrm{~mm}, 6 \mu \mathrm{m})$ linked with a TSK-Gel guard column $(6.0 \mathrm{~mm} \times 400 \mathrm{~mm})$ (Tosoh Bioscience, Stuttgart, Germany). Diluted samples were filtered $(0.45 \mu \mathrm{m})$ and eluted $(20 \mu \mathrm{L})$ with $0.1 \mathrm{M} \mathrm{NH}_{4} \mathrm{CH}_{3} \mathrm{CO}_{2}$, at a flow rate of $0.5 \mathrm{~mL} \mathrm{~min}^{-1}$ for $50 \mathrm{~min}$ at $30^{\circ} \mathrm{C}$. The detection was carried out on an ELSD System 1260 Infinity (Agilent Technologies, Boebligen, Germany). Pullulans of $M_{\mathrm{w}} 805,200,10,1.3$ and 0.34 kDa were used as calibration standards.

\subsection{Enzymatic characterization of rat small intestine extract}

2.4.1. Protein determination. Protein quantification was done through the Bradford method. ${ }^{18}$ Bovine Serum Albumin (BSA) was used as a standard and absorbance was measured at $595 \mathrm{~nm}$.

2.4.2. Enzymatic activities. Sucrase, melibiase and inulinase activities of RSIE were established by GC-FID. Firstly, solutions of sucrose, melibiose and inulin were incubated with RSIE (40 $\mathrm{mg} \mathrm{mL}^{-1}$ ) in distilled water ( $\mathrm{pH} \mathrm{6.8)} \mathrm{during} 180 \mathrm{~min}$ at $37{ }^{\circ} \mathrm{C}$ in an orbital Thermomixer comfort (Eppendorf $®$ ). Aliquots were taken in 0, 60, 120 and $180 \mathrm{~min}$ and inactivated in boiling water for $5 \mathrm{~min}$.

The carbohydrate hydrolysis was measured through GC-FID as described below. Specific enzymatic activities (U) of RSIE were calculated and expressed in $\mu$ mol per (min per $\mathrm{g}$ per protein). Each unit of specific enzymatic activity was defined as the amount of enzyme which released $1 \mu \mathrm{mol}$ of the corresponding monosaccharides in 1 min of incubation $(n=4)$.

\subsection{In vitro digestion of polysaccharides with RSIE}

The digestibility of three types of inulin, a mixture of $\alpha$-GOS and the corresponding blanks (no added carbohydrate sample) were digested with RSIE following the method used by Ferreira-Lazarte et al. $(2017)^{14}$ with slight changes. Initially, a solution of $0.5 \mathrm{mg} \mathrm{mL}^{-1}$ of prebiotic carbohydrate in distilled water was prepared, then $40 \mathrm{mg}$ of RSIE was mixed with $1 \mathrm{~mL}$ of prebiotic solution and the mixture was incubated to perform the reactions. Digestions were carried out in an orbital Thermomixer comfort (Eppendorf®) at $37{ }^{\circ} \mathrm{C}$ during $3 \mathrm{~h}$ of reaction with continuous agitation $(750 \mathrm{rpm})$. Duplicate of individual reactions were carried out for each time $(0,60$, 120 and $180 \mathrm{~min}$ ) in order to avoid any possible enzymes/substrate composition changes produced by taking aliquots, and reactions were stopped by heating in boiling water for $5 \mathrm{~min}$.

\subsection{Chromatographic analysis of carbohydrates}

Gas chromatography, equipped with a flame ionization detector (GC-FID), was used to analyze the fraction of carbohydrates for each enzymatic characterization and digestion. Samples were derivatized, to obtain trimethylsilylated oximes (TSMO) of carbohydrates, according to the method of Brobst and Lott (1966). ${ }^{19}$ Samples solutions were prepared with $500 \mu \mathrm{L}$ of 
digestion samples $(0.25 \mathrm{mg}$ of carbohydrates) and $250 \mu \mathrm{L}$ of phenyl- $\beta$-D-glucoside (internal standard, $0.5 \mathrm{mg} \mathrm{mL} \mathrm{m}^{-1}$ ), and were evaporated under vacuum. Three hundred $\mu \mathrm{L}$ of hydroxylamine chloride in pyridine $(2.5 \%, \mathrm{w} / \mathrm{v})$ were added to the samples and incubated at $70{ }^{\circ} \mathrm{C}$ for $30 \mathrm{~min}$ with agitation. Then, $300 \mu \mathrm{L}$ of hexamethyldisilazane (HDMS) and $30 \mu \mathrm{L}$ of trifluoroacetic acid (TFA) were added and heated at $50{ }^{\circ} \mathrm{C}$ for 30 min under continuous agitation. Finally, samples were centrifuged at $10000 \mathrm{rpm}$ for $3 \mathrm{~min}$. Supernatants were injected in GC-FID.

GC-FID analysis was carried out in an Agilent Technologies 7820A gas chromatograph system. Separations of the compounds were achieved with a fused silica capillary column DB-5HT (5\% phenyl methylpolysiloxane, $30 \mathrm{~m} \times 0.25 \mathrm{~mm} \times$ $0.1 \mu \mathrm{m}$, Agilent J\&W Scientific, Folsom, CA, USA). The initial oven temperature was $150{ }^{\circ} \mathrm{C}$, then increased at a rate of $3{ }^{\circ} \mathrm{C}$ $\min ^{-1}$ to $380{ }^{\circ} \mathrm{C}$. The carrier gas used was nitrogen at a flow rate of $1 \mathrm{~mL} \mathrm{~min}^{-1}$. Injector and detector temperatures were set at 280 and $385{ }^{\circ} \mathrm{C}$, respectively. Split mode $1: 20$ were used for the injections.

Interpretation and identification of the TMSO derivatives were performed using Agilent ChemStation software (Washington, DE, USA). Quantitative analysis was obtained through the internal standard method, thus calculating the response factors of standards solutions of carbohydrates (D-fructose, D-galactose, D-glucose, sucrose, lactose, kestose, nystose) at known concentrations ( 0.005 to $1 \mathrm{mg} \mathrm{mL}^{-1}$ ).

\subsection{Statistical analysis}

All digestions were made in duplicate and two GC-FID analysis $(n=2)$. For the statistical analysis, comparisons were made using analysis of variance (ANOVA) and Tukey's post hoc test with SPSS software for Windows (SPSS Inc., Chicago, II). Differences between content in carbohydrates were considered statistically significant when $p<0.05$.

\section{Results and discussion}

\subsection{Enzymatic characterization of RSIE}

Table 1 shows the sucrase, inulinase and melibiase activities of RSIE analyzed by GC-FID in the same conditions of digestion. Sucrase activity (42.07 U) was the highest, being 2-fold higher than melibiase activity (26.56 U) and eight times higher

Table 1 Specific enzymatic activities and protein content of Rat Small Intestine Extract (RSIE) at $37^{\circ} \mathrm{C}$ and $\mathrm{pH} 6.8$

\begin{tabular}{llc}
\hline Activity & Substrate & $U\left(\mu \mathrm{mol} \mathrm{min} \mathrm{m}^{-1} \mathrm{~g}^{-1}\right)$ \\
\hline Sucrase & Sucrose & $42.1 \pm 2.6^{a}$ \\
Inulinase & Inulin & $5.5 \pm 0.1^{a}$ \\
Melibiase & Melibiose & $26.6 \pm 7.1^{b}$
\end{tabular}

Protein content of RSIE was $6.9 \pm 0.5 \%(w / w)$. Hydrolytic activities were calculated by measuring the carbohydrate evolution by GC-FID. ${ }^{a}$ Increase of $\mu \mathrm{mol}$ of fructose. ${ }^{b}$ Increase of $\mu \mathrm{mol}$ of galactose. than inulinase (5.46 U). Sucrase activity obtained was moderately higher than the values obtained in previous reports in rats by Ferreira-Lazarte et al. $(2017)^{14}$ (23.5 U). These differences could be due to the variability between the batches of commercial intestinal acetone powders from rat. Regarding inulinase and melibiase activity, no previous studies have reported these activities in these enzymatic substrates.

RSIE is a complex mixture of proteins, cells, lipids, enzymes and other carbohydrates contained in the small intestine. Sucrose $(\beta$-D-Fru( $2 \rightarrow 1)$ - $\alpha$-D-Glc) and melibiose $(\alpha$-D-Gal $(1 \rightarrow 6)$ D-Glc) hydrolysis can be attributed to the sucrase-isomaltase complex. ${ }^{20}$ Sucrase site splits glucose and fructose, while isomaltase site splits Glc-Glc $\alpha(1 \rightarrow 4)$ and $\alpha(1 \rightarrow 6)$ linkages, being one of the most common complexes in the small intestine. ${ }^{21}$ Inulinase activity showed the lowest value, which could be related to the low digestibility of prebiotic fructans. ${ }^{14,22}$

\subsection{Characterization of prebiotic carbohydrates}

The chromatographic profiles corresponding to the molecular weight $\left(M_{\mathrm{w}}\right)$ distribution of carbohydrates used in the digestion assays are showed in Fig. 1. Raftiline HP had the highest $M_{\mathrm{w}}(3.4 \mathrm{kDa}-19 \mathrm{DP})$, followed by Inulin Orafti GR $(2.6 \mathrm{kDa}$; 14.5 DP); Raftilose P95 and AlphaGOS $\mathrm{P}$ presented similar values (0.6 and $0.7 \mathrm{kDa}$ and 3.3 and $4.0 \mathrm{DP}$, respectively); and melibiose the lowest ( $0.4 \mathrm{kDa}$; $2.2 \mathrm{DP})$. Raftiline HP is reported to be a polysaccharide composed of mainly inulin, with a high DP (10-60) and higher $M_{\mathrm{w}}{ }^{23-26}$ A similar situation occurs with inulin Orafti GR, although a slightly lower $M_{\mathrm{w}}$ inulin was observed in this case. ${ }^{26-28}$ Raftilose P95 and AlphaGOS P oligosaccharides showed the lowest $M_{\mathrm{w}}, 0.6 \mathrm{kDa}(3.3 \mathrm{DP})$ and $0.7 \mathrm{kDa}$ (4.0 DP), respectively. ${ }^{23,24,28-30}$

\subsection{Digestion of prebiotic carbohydrates using RSIE}

The digestibility of three recognized prebiotics (Inulin Orafti GR, Raftiline HP and Raftilose P95) and two potential prebiotic carbohydrates (AlphaGOS $\mathrm{P}$ and melibiose) were tested using RSIE. Blank samples of digestion without carbohydrates were also carried out to measure possible matrix effects of this complex mixture. ${ }^{31}$

Table 2 shows the individual composition of each carbohydrate incubated with RSIE, including mono-, di-, tri- and tetrasaccharide fractions. Before digestion treatments, Raftiline HP which is described as an inulin-type long-chain fructans, where DP below 10 is removed, ${ }^{32}$ did not show any carbohydrate with DP $<4$, apart from small amounts of fructose. On the other side, Inulin Orafti GR contains small amounts of FOS, detected as nystose, kestose and sucrose. Fructooligosaccharides (Raftilose P95) showed higher contents of small compounds ( $\mathrm{DP}<4)$ due to their oligosaccharide composition. Inulobiose $(\beta$-D-Fru $(2 \rightarrow 1)-\beta$-D-Fru $)$, inulotriose $(\beta$-D$\operatorname{Fru}(2 \rightarrow 1)-\beta$-D-Fru( $2 \rightarrow 1)-\beta$-D-Fru $)$, inulotetraose $(\beta$-D-Fru( $2 \rightarrow$ $1)-\beta$-D-Fru( $2 \rightarrow 1)-\beta$-D-Fru( $2 \rightarrow 1)$ - $\beta$-D-Fru $)$ and nystose were detected in Raftilose P95 samples, in agreement with the data reported by Montilla et al. (2006). ${ }^{33}$ Interestingly, the analysis of AlphaGOS $\mathrm{P}$ showed that this commercial product contains melibiose $(\alpha-\mathrm{D}-\mathrm{Gal}(1 \rightarrow 6)$-D-Glc), manninotriose $(\alpha-\mathrm{D}-\mathrm{Gal}(1 \rightarrow$ 


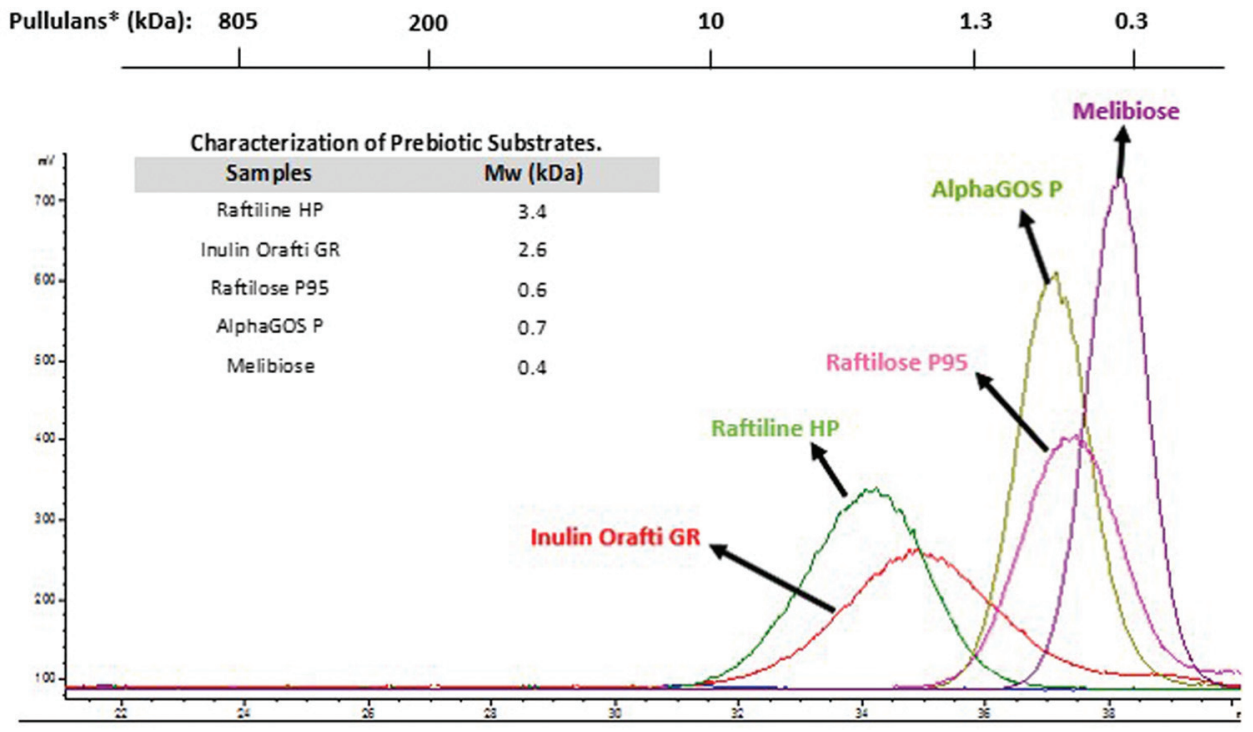

Fig. 1 Molecular weight $\left(M_{\mathrm{w}}\right)$ and chromatographic profiles by HPSEC-ELSD of prebiotic carbohydrates used in the digestion assays. ${ }^{*} M_{\mathrm{w}}$ of standards of pullulans is indicated above.

6)- $\alpha$-D-Gal( $(1 \rightarrow 6)$-D-Glc) and verbascotetraose $(\alpha$-D-Gal( $1 \rightarrow 6)$ $\alpha-\mathrm{D}-\mathrm{Gal}(1 \rightarrow 6)-\alpha-\mathrm{D}-\mathrm{Gal}(1 \rightarrow 6)-\mathrm{D}-\mathrm{Glc})$, defructosylated derivatives from the $\alpha$-galactosides raffinose, stachyose and verbascose, respectively, compounds naturally present in peas. ${ }^{34}$ This different composition may be due to the fact that original $\alpha$-galactosides could have been enzymatically treated with a fructosidase. Montilla et al. (2011), ${ }^{35}$ previously, found that this enzyme, under appropriate conditions, is able to completely eliminate the fructose from stachyose, forming manninotriose.

The evolution in the content of di-, tri- and tetrasaccharides in the samples was highly dependent on the structure during the RSIE digestion treatment. Inulin based samples such as Raftiline HP and Inulin Orafti GR exhibited the lowest changes in their composition due to the resistance of these substrates to intestinal enzymes. A minimum increase of fructose was observed in Raftiline HP possibly produced by the hydrolysis of high $M_{\mathrm{w}}$ inulin species and no bigger structures (DP $<4$ ) were detected. Regarding Inulin Orafti GR sample, slight degradations, but not significant, in the high $M_{\mathrm{w}}$ structures such as nystose (24 to $19.5 \mathrm{mg}$ nystose per $\mathrm{g}$ of sample) was registered after the digestion process (Table 2), and increases in the trisaccharide fraction were observed. Sucrose was the most digested structure causing important increases in fructose content. A similar trend was observed by Ferreira-Lazarte et al. $(2017)^{14}$ after the digestion of FOS with RSIE exhibiting the tetrasaccharide structure the highest degradation (40\%). The trisaccharide also increased, most likely, due to degradation of the tetrasaccharide. These changes are in line with the low inulinase activity measured in this extract (Table 1).

Regarding Raftilose P95, both tetrasaccharides detected showed slight but not significant degradations, being inulotetraose more hydrolyzed than nystose. A consequent increase in the corresponding trisaccharide (inulotriose) was observed after 120 min digestion, probably due to the degradation of the former. Moreover, the presence of higher DP compounds in the sample could also produce tri- and tetrasaccharides during the digestion treatment. ${ }^{29}$ Increases in smaller structures such as disaccharides (inulobiose) and monosaccharides (fructose) were also observed due to the hydrolysis of the biggest compounds.

These results underline the relevance of the higher $M_{\mathrm{w}}$ composition in terms of digestibility. ${ }^{16,36}$ Higher hydrolysis in Inulin Orafti GR was observed in the tetrasaccharide fraction after 180 min of digestion, supporting the data obtained in the in vivo and in vitro studies by Ferreira-Lazarte et al. $(2017)^{14}$ and Molis et al. (1996), ${ }^{37}$ resulting in $12 \%$ and $11 \%$ of total digestion, respectively. In the case of Raftilose P95, a not significant decrease of tri- and tetrasaccharides was observed: hydrolysis being higher in the case of the linkage $\beta(2 \rightarrow 1)$ between fructose monomers (inulotriose and inulotetraose of Raftilose P95), when glucose is not present in the structure ending compared to sucrose oligosaccharides (kestose and nystose of Inulin Orafti GR) (Table 2). This could suggest the lower resistance of the $\beta(2 \rightarrow 1)$ bonds to the action of the digestive enzymes. ${ }^{14}$

With respect to oligosaccharides from galactose, chromatographic profiles by GC-FID of AlphaGOS P undigested and after digestion with RSIE are shown in Fig. 2. A decrease of verbascotetraose and manninotriose was observed (peaks 4 and 5) and, consequently, melibiose and galactose contents were increased after $180 \mathrm{~min}$ of digestion due to the degradation of the structures with higher $M_{\mathrm{w}}$ (Table 2). However, decreases in the melibiose levels were detected when a standard of only melibiose was digested, showing the highest hydrolysis values $(67.7 \%)$ after $180 \mathrm{~min}$ of digestion. This degradation is in accordance with the considerable previous melibiase activity detected in the enzymatic extract, thus suggesting that the 


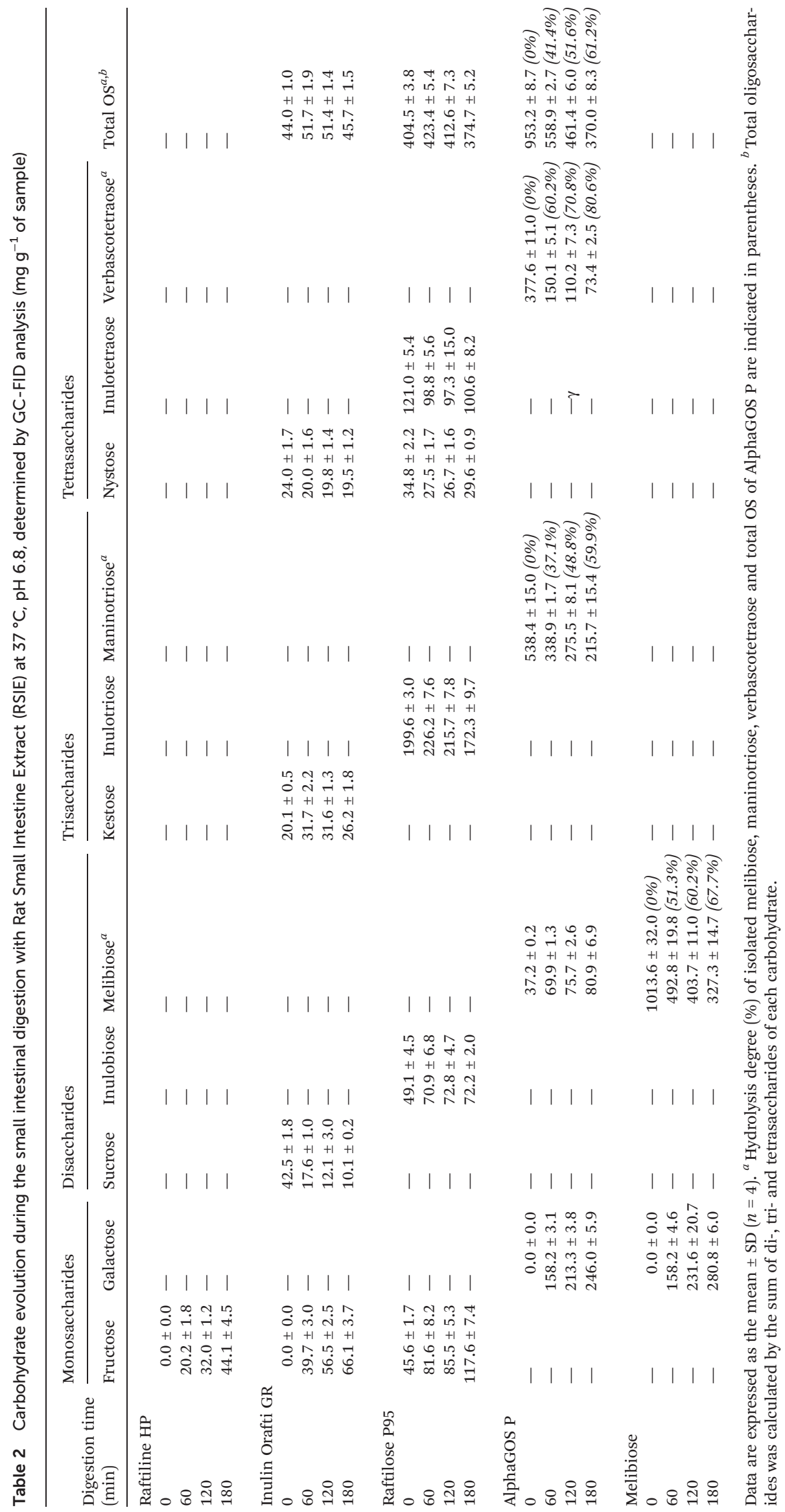




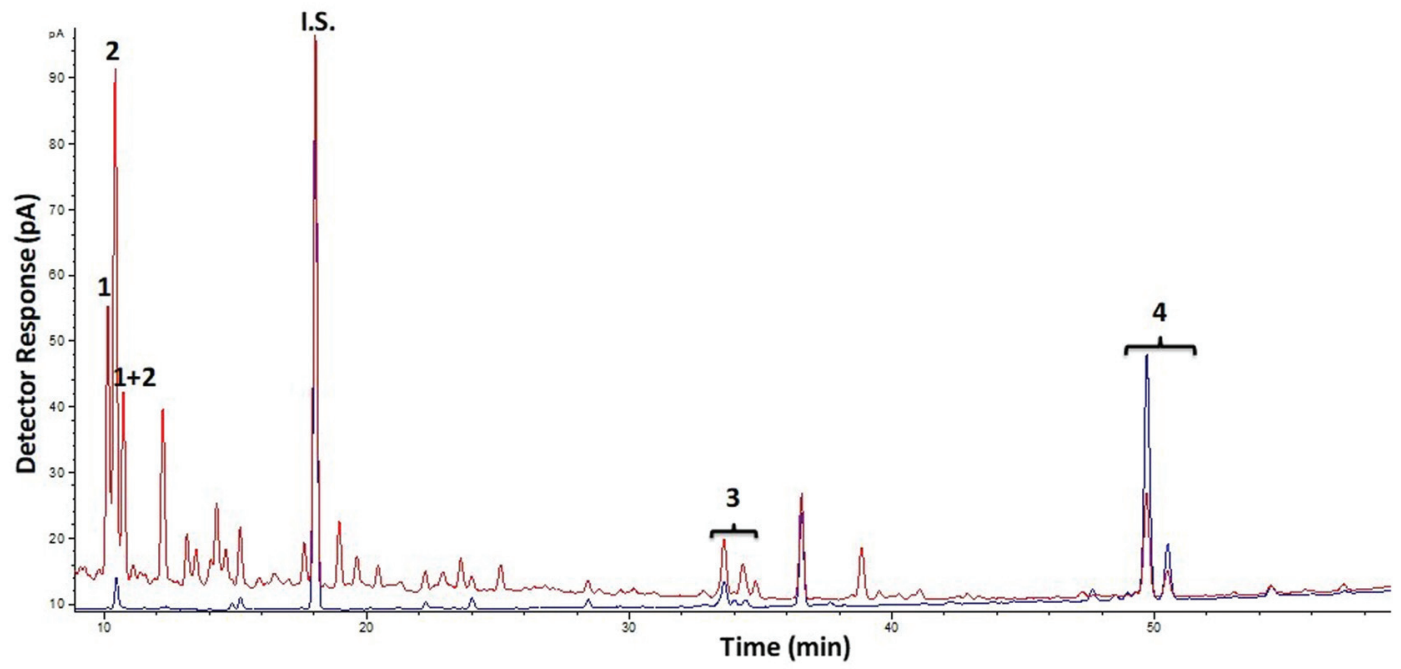

Fig. 2 Chromatographic profiles obtained by GC-FID of TMSO derivatives of oligosaccharides present in AlphaGOS P before (blue) and after $180 \mathrm{~min}$ of small intestinal digestion with RSIE (red). Peaks: 1. Galactose, 2: glucose, i.s.: internal standard, 3: melibiose, 4: maninotriose, 5: verbascotetraose.

intestinal enzymes probably are more prone to hydrolyze higher $M_{\mathrm{w}}$ structures present in the sample (manninotriose and verbascotetraose) rather than the disaccharide.

Increases in galactose levels also suggest that linkages between galactose monomers are being broken by digestive enzymes, similar to the degradation of $\beta$-GOS derived from lactose and lactulose observed during small intestinal digestion in previous works. ${ }^{14,16,36,38,39}$ Beneficial effect of the $\alpha$-GOS on the modulation of the intestinal microbiota is wellknown. ${ }^{40,41}$ Nevertheless, there is not enough information about their digestibility, even the expert scientific panel from the European Food Safety Authority (EFSA) claims that the $\alpha$-GOS are non-digestible carbohydrates. ${ }^{42}$ Considering the sum of total oligosaccharides of AlphaGOS P (manninotriose and verbascotetraose) the hydrolysis was considerably high $(61.2 \%)$ (Table 2), despite the lack of pancreatic $\alpha$-galactosidase in mammals. ${ }^{43}$ However, Ferreira-Lazarte et al. $(2019)^{16}$ showed meaningful hydrolysis degree of prebiotic $\beta$-GOS $(53 \%$ for linkages $\beta(1 \rightarrow 3))$ using brush border membrane vesicles of small intestine of pig. A possible explanation for this fact could be the promiscuous multienzymatic complexes in the rat small intestine extract. ${ }^{12}$ Carbohydrases of the small intestine, such as $\alpha$-amylase, hydrolyze large starch structures, whereas complete digestion is done by the mucosal $\alpha$-glucosidases. ${ }^{44,45}$ In this sense, mucosal maltase-glucoamylase and sucrase-isomaltase complexes could hydrolyze to $\alpha(1$ $\rightarrow 6$ ) bonds between the monomers of both AlphaGOS P and melibiose..$^{20,21,46}$ These enzymatic structures could also have more versatility in terms of hydrolytic activity, as was showed elsewhere. ${ }^{16,47}$ To the best of our knowledge, these data are the first evidence about digestibility of $\alpha$-GOS with small intestine enzymes.

Some in vivo studies with rats have demonstrated a partial digestibility of prebiotic carbohydrates, showing a considerable high hydrolysis rate of $\beta$-GOS obtained from lactose and lactulose. ${ }^{36,48}$ In the same way, an in vitro study with RSIE reported a hydrolysis degree of $12 \%$ of a mixture of FOS after 120 min of digestion. ${ }^{14}$ These reported data are consistent with this work, highlighting the key role of the mammalian intestinal enzymes on the digestibility of carbohydrates.

\section{Conclusions}

Limitations of traditional digestibility methods of carbohydrates have been shown in several works. ${ }^{12,13}$ Therefore, results obtained in this work confirmed the usefulness and effectiveness of the use of a RSIE to evaluate the digestion of polysaccharides. Moreover, similarities between small intestinal enzymes of rat and human emphasized the viability of this extract. ${ }^{49}$ Raftiline HP, which is mainly constituted by inulin, showed the highest resistance to the gastrointestinal enzymes, with only a slight increase of fructose. Inulin Orafti GR also showed high resistance, with a small hydrolysis of tetrasaccharides, followed by Raftilose P95, thus supporting the role of these substrates as prebiotic compounds. Finally, AlphaGOS P and melibiose showed a considerable high hydrolysis degree (61.2 and $67.7 \%$, respectively), remarking the effect of the chemical structure ( $M_{\mathrm{w}}$ and type of linkage) of prebiotic oligosaccharides with respect to their resistance to digestibility. According to the obtained results, mucosal enzymes complexes have versatile hydrolytic activities and contribute to the digestion of different types of functional fiber which is belief to reach intact the distal colon to be fermented by the microbiota exerting its beneficial effects. Therefore, although more studies are required, including in vivo analysis, the results obtained underline the need to use specific methods for carbohydrates based on small intestinal extract of mammals, to test the resistance of these compounds to digestion. 
In general, the well-known prebiotic activity of these fibers is aligned with their partial digestibility, since not all the carbohydrate fraction is digested. In consequence, it is important to highlight that not all prebiotic carbohydrates are nondigestible and can be partially digested, still exerting the beneficial effect in the large intestine, which, therefore, warrants a revision of the current assumption of non-digestibility of prebiotic carbohydrates, as recently was suggested by HernandezHernandez (2019). ${ }^{50}$

\section{Abbreviations used}

$\begin{array}{ll}\text { DP } & \text { Degree of polymerization } \\ \text { FOS } & \text { Fructooligosaccharides } \\ \text { GC-FID } & \text { Gas chromatography with flame ionization } \\ & \text { detector } \\ \text { GOS } & \text { Galactooligosaccharides } \\ \text { HP } & \text { High performance } \\ \text { HPSEC-ELSD } & \text { High performance size exclusion cromato- } \\ & \text { graphy with an evaporative light scattering } \\ & \text { detector } \\ M_{\mathrm{W}} & \text { Molecular weight } \\ \text { NDOs } & \text { Non-digestible oligosaccharides } \\ \text { RDA } & \text { Recommended daily allowance } \\ \text { RSIE } & \text { Rat small intestine extract } \\ \text { TMSO } & \text { Trimethylsilylated oximes }\end{array}$

\section{Conflicts of interest}

There are no conflicts to declare.

\section{Acknowledgements}

Authors acknowledge the finance of this work by the Spanish Ministry of Economy, Industry and Competitiveness (Project AGL2017-84614-C2-1-R) and the Spanish Ministry of Science, Innovation and Universities (Project RTI2018-101273-J-I00).

\section{References}

1 M. Van Hul and P. D. Cani, Targeting Carbohydrates and Polyphenols for a Healthy Microbiome and Healthy Weight, Curr. Nutr. Rep., 2019, 8, 307-316.

2 G. A. Soliman, Dietary Fiber, Atherosclerosis, and Cardiovascular Disease, Nutrients, 2019, 11, 1155.

3 P. C. Champe and R. A. Harvey, Biochemistry (Lippincott's illustrated reviews), Lippincott, 1994.

4 X. Qi, F. H. Al-Ghazzewi and R. F. Tester, Dietary Fiber, Gastric Emptying, and Carbohydrate Digestion: A MiniReview, Starch/Staerke, 2018, 70, 1700346.

5 A. Abdul-Hamid and S. L. Yu, Functional properties of dietary fibre prepared from defatted rice bran, Food Chem., 2000, 68, 15-19.
6 P. D. Cani and B. F. Jordan, Gut microbiota-mediated inflammation in obesity: a link with gastrointestinal cancer, Nat. Rev. Gastroenterol. Hepatol., 2018, 15, 671-682.

7 E. S. Chambers, T. Preston, G. Frost and D. J. Morrison, Role of gut Microbiota-Generated short-chain fatty acids in metabolic and cardiovascular health, Curr. Nutr. Rep., 2018, 7, 198-206.

8 P. Louis and H. J. Flint, Formation of propionate and butyrate by the human colonic microbiota, Environ. Microbiol., 2017, 19, 29-41.

9 A. Brodkorb, L. Egger, M. Alminger, P. Alvito, R. Assunção, S. Ballance, T. Bohn, C. Bourlieu-Lacanal, R. Boutrou, F. Carriere, A. Clemente, M. Corredig, D. Dupont, C. Dufour, C. Edwards, M. Golding, S. Karakaya, B. Kirkhus, S. Le Feunteun, U. Lesmes, A. Macierzanka, A. R. Mackie, C. Martins, S. Marze, D. J. McClements, O. Ménard, M. Minekus, R. Portman, C. N. Santos, I. Souchon, R. P. Singh, G. E. Vegarud, M. S. J. Wickhman, W. Weitschies and I. Recio, INFOGEST static in vitro simulation of gastrointestinal food digestion, Nat. Protoc., 2019, 14, 991-1014.

10 B. V. Mccleary, J. W. De Vries, J. I. Rader, G. Cohen, L. Prosky, D. C. Mugford, M. Champ and K. Okuma, Determination of total dietary fiber (CODEX definition) by enzymatic-gravimetric method and liquid chromatography: Collaborative study, J. AOAC Int., 2010, 93, 221-233.

11 B. V. McCleary, N. Sloane and A. Draga, Determination of total dietary fibre and available carbohydrates: A rapid integrated procedure that simulates in vivo digestion, Starch/ Staerke, 2015, 67, 860-883.

12 A. Ferreira-Lazarte, In vitro digestibility and fermentability of selected prebiotics and functional carbohydrates with prebiotic potential, PhD Thesis, Universidad Autónoma de Madrid, 2019.

13 K. Tanabe, S. Nakamura and T. Oku, Inaccuracy of AOAC method 2009.01 with amyloglucosidase for measuring nondigestible oligosaccharides and proposal for an improvement of the method, Food Chem., 2014, 151, 539-546.

14 A. Ferreira-Lazarte, A. Olano, M. Villamiel and F. J. Moreno, Assessment of in vitro digestibility of dietary carbohydrates using rat small intestinal extract, J. Agric. Food Chem., 2017, 65, 8046-8053.

15 A. Ferreira-Lazarte, A. Montilla, A. I. Mulet-Cabero, N. Rigby, A. Olano, A. Mackie and M. Villamiel, Study on the digestion of milk with prebiotic carbohydrates in a simulated gastrointestinal model, J. Funct. Foods, 2017, 33, 149-154.

16 A. Ferreira-Lazarte, P. Gallego-Lobillo, F. J. Moreno, M. Villamiel and O. Hernandez-Hernandez, In vitro digestibility of galactooligosaccharides: effect of the structural features on their intestinal degradation, J. Agric. Food Chem., 2019, 67, 4662-4670.

17 N. Muñoz-Almagro, F. Rico-Rodriguez, M. Villamiel and A. Montilla, Pectin characterisation using size exclusion chromatography: A comparison of ELS and RI detection, Food Chem., 2018, 252, 271-276. 
18 M. M. Bradford, A rapid and sensitive method for the quantitation of microgram quantities of protein utilizing the principle of protein-dye binding, Anal. Biochem., 1976, 72, 248-254.

19 K. M. Brobst and C. E. Lott Jr., Determination of some components in corn syrup by gas-liquid chromatography of the trimethylsilyl derivatives, Cereal Chem., 1966, 43, 35-43.

20 J. Feher, Digestion and absorption of the macronutrients, in Quantitative human physiology, Academic Press, 2012, 731-743.

21 D. Hooton, R. Lentle, J. Monro, M. Wickham and R. Simpson, The secretion and action of brush border enzymes in the mammalian small intestine, in Reviews of physiology, biochemistry and pharmacology, Springer Cham, 2015, 168, 59-11.

22 R. A. Rastall, Functional oligosaccharides: application and manufacture, Annu. Rev. Food Sci. Technol., 2010, 1, 305339.

23 A. Franck, Technological functionality of inulin and oligofructose, Br. J. Nutr., 2002, 87, S287-S291.

24 M. A. Mensink, H. W. Frijlink, K. van der Voort Maarschalk and W. L. Hinrichs, Inulin, a flexible oligosaccharide I: Review of its physicochemical characteristics, Carbohydr. Polym., 2015, 130, 405-419.

25 L. A. Schaller-Povolny, D. E. Smith and T. P. Labuza, Effect of water content and molecular weight on the moisture isotherms and glass transition properties of inulin, Int. J. Food Prop., 2000, 3, 173-192.

26 Á. Ávila-Fernández, E. Cuevas-Juárez, M. E. RodríguezAlegría, C. Olvera and A. López-Munguía, Functional characterization of a novel $\beta$-fructofuranosidase from Bifidobacterium longum, subsp. infantis ATCC 15697 on structurally diverse fructans, J. Appl. Microbiol., 2016, 121, 263-276.

27 Product Sheet DOC.A4-03/001 Orafti ${ }^{\circledR}$ GR, Beneo-Orafti S.A, Tienen, Belgium, 2016.

28 K. H. Han, H. Tsuchihira, Y. Nakamura, K. I. Shimada, K. Ohba, T. Aritsuka, H. Uchino, H. Kikuchi and M. Fukushima, Inulin-type fructans with different degrees of polymerization improve lipid metabolism but not glucose metabolism in rats fed a high-fat diet under energy restriction, Dig. Dis. Sci., 2013, 58, 2177-2186.

29 C. Nobre, S. C. Sousa, S. P. Silva, A. C. Pinheiro, E. Coelho, A. A. Vicente, A. M. P. Gomes, M. A. Coimbra, J. A. Teixeira and L. R. Rodrigues, In vitro digestibility and fermentability of fructo-oligosaccharides produced by Aspergillus ibericus, J. Funct. Foods, 2018, 46, 278-287.

30 C. Blecker, C. Fougnies, J. C. Van Herck, J. P. Chevalier and M. Paquot, Kinetic study of the acid hydrolysis of various oligofructose samples, J. Agric. Food Chem., 2003, 50, 16021607.

31 A. Pyner, H. Nyambe-Silavwe and G. Williamson, Inhibition of human and rat sucrase and maltase activities to assess antiglycemic potential: Optimization of the assay using acarbose and polyphenols, J. Agric. Food Chem., 2017, 65, 8643-8651.
32 G. Kelly, Inulin-type prebiotics-a review: part 1, Altern. Med. Rev., 2008, 13, 315-329.

33 A. Montilla, J. Van de Lagemaat, A. Olano and M. D. Del Castillo, Determination of oligosaccharides by conventional high-resolution gas chromatography, Chromatographia, 2006, 63, 453-458.

34 N. Moussou, M. Corzo-Martínez, M. L. Sanz, F. Zaidi, A. Montilla and M. Villamiel, Assessment of Maillard reaction evolution, prebiotic carbohydrates, antioxidant activity and $\alpha$-amylase inhibition in pulse flours, J. Food Sci. Technol., 2017, 54, 890-900.

35 A. Montilla, A. Olano, C. Martínez-Villaluenga and N. Corzo, Study of influential factors on oligosaccharide formation by fructosyltransferase activity during stachyose hydrolysis by Pectinex Ultra SP-L, J. Agric. Food Chem., 2011, 59, 10705-10711.

36 O. Hernández-Hernández, M. C. Marín-Manzano, L. A. Rubio, F. J. Moreno, M. L. Sanz and A. Clemente, Monomer and linkage type of galacto-oligosaccharides affect their resistance to ileal digestion and prebiotic properties in rats, J. Nutr., 2012, 142, 1232-1239.

37 C. Molis, B. Flourie, F. Ouarne, M. F. Gailing, S. Lartigue, A. Guibert, F. Bornet and J. P. Galmiche, Digestion, excretion, and energy value of fructooligosaccharides in healthy humans, Am. J. Clin. Nutr., 1996, 64, 324-328.

38 L. C. Julio-Gonzalez, O. Hernandez-Hernandez, F. J. Moreno, A. Olano, M. L. Jimeno and N. Corzo, Trans$\beta$-galactosidase activity of pig enzymes embedded in the small intestinal brush border membrane vesicles, Sci. Rep., 2019, 9, 960.

39 Y. Shi, J. Liu, Q. Yan, X. You, S. Yang and Z. Jiang, In vitro digestibility and prebiotic potential of curdlan $(1 \rightarrow 3)$ $\beta$-D-glucan oligosaccharides in Lactobacillus species, Carbohydr. Polym., 2018, 188, 17-26.

40 Q. Chen, M. Liu, P. Zhang, S. Fan, J. Huang, S. Yu, C. Zhang and H. Li, Fucoidan and galactooligosaccharides ameliorate high-fat diet-induced dyslipidemia in rats by modulating the gut microbiota and bile acid metabolism, Nutrition, 2019, 65, 50-59.

41 S. Yousefi, S. H. Hoseinifar, H. Paknejad and A. Hajimoradloo, The effects of dietary supplement of galactooligosaccharide on innate immunity, immune related genes expression and growth performance in zebrafish (Danio rerio), Fish Shellfish Immunol., 2018, 73, 192-196.

42 EFSA Panel on Dietetic Products, Nutrition and Allergies (NDA), Scientific Opinion on the substantiation of a health claim related to AlphaGOS ${ }^{\circledR}$ and a reduction of post-prandial glycaemic responses pursuant to Article 13 (5) of Regulation (EC) No 1924/2006, EFSA J., 2014, 12, 3838.

43 J. G. LeBlanc, M. S. Garro, A. Silvestroni, C. Connes, J. C. Piard, F. Sesma and G. Savoy de Giori, Reduction of $\alpha$-galactooligosaccharides in soyamilk by Lactobacillus fermentum CRL 722: in vitro and in vivo evaluation of fermented soyamilk, J. Appl. Microbiol., 2004, 97, 876-881.

44 B. H. Lee and B. R. Hamaker, Number of branch points in $\alpha$-limit dextrins impact glucose generation rates by mam- 
malian mucosal $\alpha$-glucosidases, Carbohydr. Polym., 2017, 157, 207-213.

45 H. Shin, D. H. Seo, J. Seo, L. M. Lamothe, S. H. Yoo and B. H. Lee, Optimization of in vitro carbohydrate digestion by mammalian mucosal $\alpha$-glucosidases and its applications to hydrolyze the various sources of starches, Food Hydrocolloids, 2019, 87, 470-476.

46 A. C. Dona, G. Pages, R. G. Gilbert and P. W. Kuchel, Digestion of starch: In vivo and in vitro kinetic models used to characterise oligosaccharide or glucose release, Carbohydr. Polym., 2010, 80, 599-617.

47 B. H. Lee, D. R. Rose, A. H. M. Lin, R. Quezada-Calvillo, B. L. Nichols and B. R. Hamaker, Contribution of the indi- vidual small intestinal $\alpha$-glucosidases to digestion of unusual $\alpha$-linked glycemic disaccharides, J. Agric. Food Chem., 2016, 64, 6487-6494.

48 E. Jantscher-Krenn, C. Marx and L. Bode, Human milk oligosaccharides are differentially metabolised in neonatal rats, Br. J. Nutr., 2013, 110, 640-650.

49 T. Oku, K. Tanabe, S. Ogawa, N. Sadamori and S. Nakamura, Similarity of hydrolyzing activity of human and rat small intestinal disaccharidases, Clin. Exp. Grastroenterol., 2011, 4, 155-161.

50 O. Hernandez-Hernandez, In vitro Gastrointestinal Models for Prebiotic Carbohydrates: A Critical Review, Curr. Pharm. Des., 2019, 25, 3478-3483. 